\title{
Pheochromocytoma presenting as musculoskeletal pain from bone metastases
}

\author{
Matthew D. Lynn, M.D., Ethan M. Braunstein, M.D., and Brahm Shapiro, M.B., Ch.B., Ph.D. \\ Departments of ${ }^{1}$ Radiology and ${ }^{2}$ Internal Medicine, Division of Nuclear Medicine, University of Michigan Medical Center, \\ Ann Arbor, Michigan, USA
}

\begin{abstract}
Six patients presented with musculoskeletal pain resulting from destructive bone lesions. These patients were ultimately shown to have metastatic pheochromocytoma. None of the cases exhibited typical symptoms of metastatic pheochromocytoma, nor was it suspected at the time of presentation. In three patients, hypertension caused pheochromocytoma to be considered as a diagnosis. The three remaining patients, all of whom had documented hypertension in the past, underwent bone biopsy. Two of these patients became markedly hypertensive in the postoperative period. Malignant pheochromocytoma may present with metastatic skeletal disease in some patients in whom the presence of hypertension as well as a carefully elicited history may suggest the diagnosis. In such patients, the possibility of pheochromocytoma should be taken into account, as biopsy may trigger a hypertensive crisis in patients not under adrenergic blockade.
\end{abstract}

Key words: Pheochromocytoma - Metastasis in bone - Bone biopsy under adrenergic blockade

Pheochromocytoma is a rare catecholamine-releasing tumor which is benign in approximately $90 \%$ of cases $[4,7,11]$. This tumor, even when widely metastatic, typically presents with symptoms such as headache, dizziness, flushing, and palpitations $[4,7,11]$ that are related to increased circulating catecholamines. Hypertension, either episodic or sustained, is present in over $90 \%$ of pheochromocytoma patients [8]. Pheochromocytoma accounts

Address reprint requests to: Matthew D. Lynn, M.D., Department of Radiology - Box 0030, University of Michigan Hospitals, 1500 E. Medical Center Drive, Ann Arbor, MI 48109, USA for approximately $0.1 \%$ of all patients with diastolic hypertension [9]. Other physical findings include tachycardia, sweating, and pallor.

Review of 56 patients with metastatic pheochromocytoma yielded six patients whose presenting symptom was musculoskeletal pain secondary to destructive bone lesions, all later determined to be pheochromocytoma bone metastases. Although malignant pheochromocytoma will be diagnosed in very few cases of destructive bone lesions from an unknown cause, this diagnosis must be considered because of the potentially lethal side effects of bone biopsy in patients not under adrenergic blockade.

\section{Material and methods}

We reviewed medical records of 56 patients with metastatic pheochromocytoma evaluated at the University of Michigan from 1980 to 1985 . Six patients presented with musculoskeletal pain. All radiographic and scintigraphic studies available on these patients were reviewed. Plasma catecholamines were determined by radioenzymatic assay on samples drawn through an indwelling needle in resting, supine, and fasting conditions [13]. Iodine-131-MIBG scintigraphy was performed using $0.5 \mathrm{mCi}^{131} \mathrm{I}-\mathrm{MIBG}$ as previously described [16].

\section{Results}

The findings in the six cases are summarized in Table 1. The patient group consisted of five men and one woman, 13 to 56 years of age. In all cases the diagnosis was confirmed by elevated catecholamine levels. On initial history, none of the patients complained of symptoms typically associated with pheochromocytoma (i.e., headache, sweating, palpitation, flushing, and dizziness). In retrospect three patients had experienced symptoms that were probably related to hypercatecholaminemia. Four patients were hypertensive when examined. Blood 
Table 1.

\begin{tabular}{|c|c|c|c|c|c|c|c|}
\hline \multirow[t]{2}{*}{ Patient } & \multirow{2}{*}{$\begin{array}{l}\text { Age } \\
\text { (years) }\end{array}$} & \multirow[t]{2}{*}{ Sex } & \multirow[t]{2}{*}{ Complaint } & \multirow{2}{*}{$\begin{array}{l}\text { History and physical } \\
\text { findings at presentation }\end{array}$} & \multirow{2}{*}{$\begin{array}{l}\text { Radiographic } \\
\text { findings }\end{array}$} & \multicolumn{2}{|c|}{ Plasma catecholamine levels } \\
\hline & & & & & & $\begin{array}{l}\text { Norepinephrine } \\
(\mathrm{pg} / \mathrm{ml}) \\
{[\mathrm{nl}<500]}\end{array}$ & $\begin{array}{l}\text { epinephrine } \\
(\mathrm{pg} / \mathrm{ml}) \\
{[\mathrm{nl}<100]}\end{array}$ \\
\hline 1 & 15 & M & $\begin{array}{l}\text { Back pain after } \\
\text { minor football } \\
\text { injury }\end{array}$ & $\begin{array}{l}\text { BP } 180 / 130 \\
\text { Developed sweating, } \\
\text { pallor, lightheadness } \\
\text { after injury }\end{array}$ & $\begin{array}{l}\text { Absent right } \\
\text { T6 pedicle }\end{array}$ & 1733 & 194 \\
\hline 2 & 36 & $F$ & Left hip pain & $\begin{array}{l}\text { BP } 150 / 100 \\
\text { Headache diagnosed as } \\
\text { migraine. Hypertensive } \\
\text { episodes during pregnancy }\end{array}$ & $\begin{array}{l}\text { Expansile lesion, } \\
\text { left pelvis }\end{array}$ & 8156 & 121 \\
\hline 3 & 53 & M & Right hip pain & $\begin{array}{l}\text { Four-year history of } \\
\text { hypertension. Symptoms } \\
\text { of pheochromocytoma in } \\
\text { retrospect }\end{array}$ & $\begin{array}{l}\text { Destructive lesion, } \\
\text { right ilium }\end{array}$ & 1978 & 2090 \\
\hline 4 & 13 & M & $\begin{array}{l}\text { Back pain and } \\
\text { abnormal gait }\end{array}$ & BP $180 / 120$ & $\begin{array}{l}\text { Destructive lesions, } \\
\text { multiple thoracic } \\
\text { and lumbar } \\
\text { vertebral bodies }\end{array}$ & 5385 & 72 \\
\hline 5 & 30 & $\mathrm{M}$ & Back pain & $\begin{array}{l}\text { BP } 250 / 140 \\
\text { Microscopic hematuria }\end{array}$ & $\begin{array}{l}\text { Destructive } \\
\text { lesion } \mathrm{T} 8\end{array}$ & 5922 & 235 \\
\hline 6 & 56 & M & $\begin{array}{l}\text { Right shoulder } \\
\text { and left thigh } \\
\text { pain }\end{array}$ & $\begin{array}{l}\text { Long-term difficulty } \\
\text { controlling hypertension }\end{array}$ & $\begin{array}{l}\text { Permeative lesions } \\
\text { in right humerus } \\
\text { and left femur }\end{array}$ & 1477 & 654 \\
\hline
\end{tabular}

pressure readings were not available on the remaining two patients, but both had histories of hypertension.

Three patients presented with back pain, two with hip pain, and one with shoulder and thigh pain. Radiographic abnormalities were present in all six patients. Findings of bone destruction ranged from lytic lesions mixed with reactive sclerosis (Fig. 1, patient 2) to purely permeative lytic lesions (Fig. 2, patient 6). Three patients presented with back pain referable to spinal lesions (Fig. 3, patient 5).

In three cases, hypertension suggested the diagnosis of pheochromocytoma, but the three remaining patients underwent bone biopsy despite past documented hypertension. Two of these patients became markedly hypertensive in the postoperative period, with systolic blood pressures of over $200 \mathrm{~mm} \mathrm{Hg}$. All three biopsies were misinterpreted initially and were only read correctly upon review. In two cases (patients 2 and 3), the initial biopsy interpretation was anaplastic small cell tumor. In patient 6 , the biopsy was initially interpreted as transitional cell carcinoma.

In all six patients, ${ }^{131}$ I-MIBG scans were positive (i.e., demonstrated at least one abnormal focus of radiopharmaceutical uptake). A focus of ${ }^{131} \mathrm{I}$ -
MIBG uptake corresponding to the symptomatic bone lesions was demonstrated in five of six cases (all but patient 5).

\section{Discussion}

Metastatic pheochromocytoma may present with musculoskeletal pain from bone metastases. This is not surprising since bone is the most common site of metastasis in this disease $[5,6,12,15]$. We have recently reviewed the radiographic appearance of bone metastases from pheochromocytoma [5]. Radiographic findings were found to vary, ranging from lytic-permeative to expansile-geographic (with or without reactive sclerosis). The bone lesions in this series show a similar spectrum of radiographic findings, from lytic permeative (patient 6) to expansile-geographic mixed with reactive sclerosis (patient 2 ).

Reasons for the lack of obvious symptoms related to hypercatecholaminemia are unclear. In three patients, these symptoms were present, but their significance was not appreciated until after the diagnosis was made.

Although only a very small number of patients who present with destructive bone lesions from an unknown cause will be shown to have pheochro- 

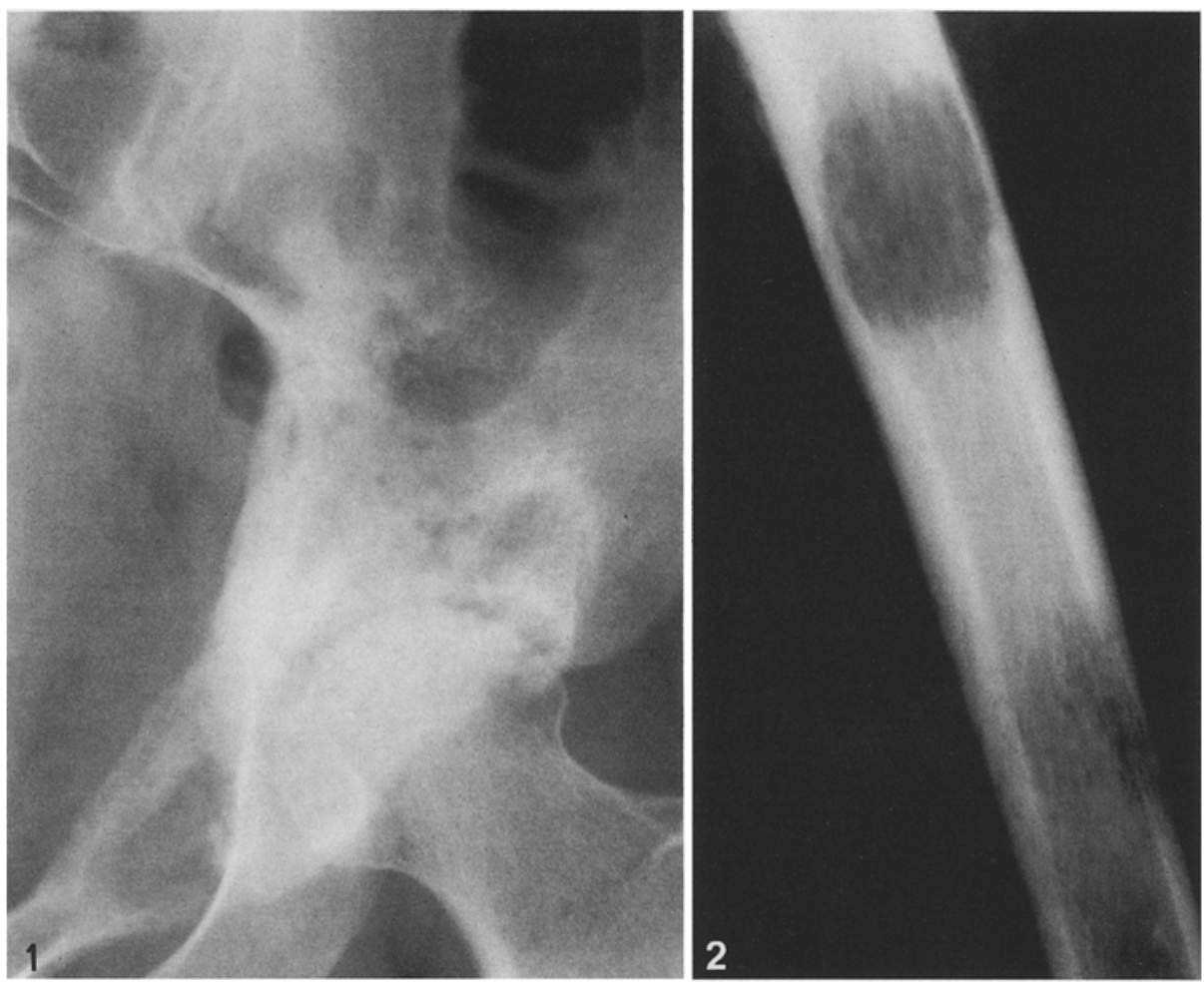

Fig. 1. Expansile mixed lytic and sclerotic pheochromocytoma metastasis involving the left pelvis of a 36-year-old woman (patient 2) who presented with left hip pain

Fig. 2. Two permeative pheochromocytoma metastases in the proximal left femur of a 56year-old man (patient 6) who presented with left thigh and right shoulder pain. He had a lesion with a similar appearance in the proximal right humerus

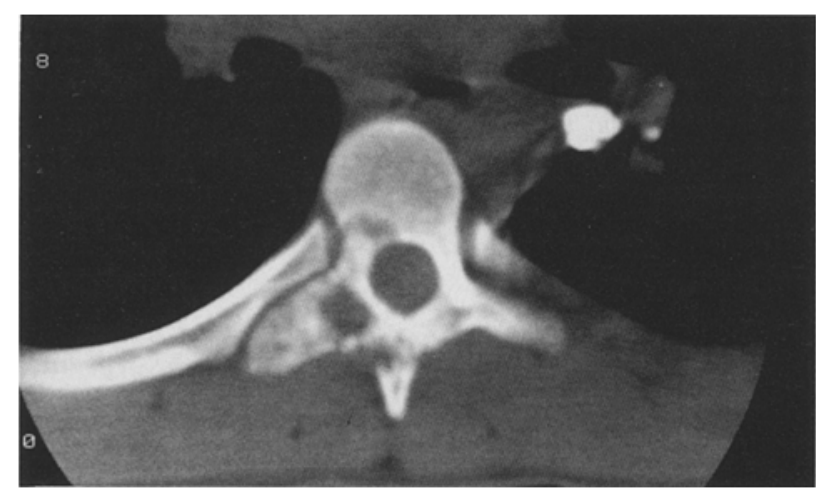

Fig. 3. CT scan demonstrating an expansile mixed lytic and sclerotic pheochromocytoma metastasis involving the right posterior elements and posterior vertebral body at the level of T8 in a 30-year-old man (patient 5) who presented with back pain

mocytoma, the diagnosis should be considered because bone biopsy in patients without adrenergic blockade may result in severe complications. General anesthesia and tumor manipulation may cause a sudden increase in circulating catecholamine levels, precipitating a hypertensive crisis or arrhythmia [4, 7]. Pheochromocytoma is a highly vascular lesion, and although there are no reported instances of difficulty with hemostasis during biopsy of bone metastases from this tumor, the potential for this complication exists. Massive blood loss, hypertensive episodes, and cardiac arrest have all occurred during resection of intra-abdominal pheochromocytomas [4, 7]. Hypertensive episodes occurred in two of the three patients in our series who underwent bone biopsy.

When a patient presents with a destructive bone lesion from an unknown cause, we recommend taking a careful history, with particular attention to symptoms associated with hypercatecholaminemia (including headache, dizziness, flushing, and palpitations), and performing a careful examination for the physical findings of pheochromocytoma (including hypertension, tachycardia, sweating, and pallor). All the patients in our series were either hypertensive at presentation or had a history of hypertension. Three had a history of symptoms that were probably related to hypercatecholaminemia, but these were recognized only in retrospect.

Further investigations prior to bone biopsy should include biochemical measurements such as serum and/or urinary catecholamines. These studies have relatively high sensitivity and specificity $[1,3,7]$. In addition, abdominal computed tomography and ${ }^{131}$ I-MIBG scintigraphy should be considered. Iodine-131-MIBG scintigraphy is positive in the majority of pheochromocytomas, both primary and secondary $[10,15]$. Ninety percent of primary pheochromocytomas are adrenal, and 
most of the remainder are extra-adrenal but intraabdominal [2]. Thus a negative abdominal CT scan will exclude a diagnosis of metastatic pheochromocytoma in the majority of cases. Because contrast material has occasionally induced hypertensive crises in unblocked patients [14], alpha adrenergic blockade should be instituted prior to IV contrast administration in any patient with suspected pheochromocytomas.

\section{References}

1. Bravo El, Tarazi RC, Gifford RW, Stewart BH (1979) Circulating and urinary catecholamines in pheochromocytoma: diagnostic and pathophysiologic implications. $\mathrm{N}$ Engl J Med 301:682

2. Francis IR, Glazer GM, Shapiro B (1983) Complementary roles of CT and ${ }^{131} \mathrm{I}-\mathrm{MIBG}$ scintigraphy in pheochromocytoma. AJR 141:719

3. Freier DT, Harrison TS, Donahue SM (1973) Rigorous biochemical criteria for the diagnosis of pheochromocytoma. J Surg Res 14:177

4. Freier DT, Eckhauser FE, Harrison FS (1980) Pheochromocytoma: a persistently problematic and still potentially lethal disease. Arch Surg 115:388

5. Lynn MD, Braunstein EM, Shapiro B (1986) Bone metastases in pheochromocytoma: comparative studies of efficacy of imaging. Radiology 160:701

6. Mahoney EM, Harrison JH (1977) Malignant pheochromocytoma: clinical course and treatment. J Urol 118:225
7. Manger WM, Gifford RW (1982) Hypertension secondary to pheochromocytoma. Bull NY Acad Med 58:139

8. Manger WM, Gifford RW (1977) Pheochromocytoma. Springer, New York, p 94

9. Manger WM, Gifford RW (1977) Pheochromocytoma. Springer, New York, $\mathrm{p} 2$

10. McEwan AJ, Shapiro B, Sisson JC, Beierwaltes WH, Ackery DM (1985) Radioiodobenzylguanidine for the scintigraphic location and therapy of adrenergic tumors. Semin Nucl Med 15:132

11. Modlin IN, Farndon JR, Shepherd A, Jonston IDA, Kennedy PC, Montgomery DAD, Welbourn RB (1979) Pheochromocytoma in 72 patients: clinical and diagnostic features, treatment and long-term results. Br J Surg 66: 456

12. Palmieri G, Ikkos D, Luft R (1961) Malignant pheochromocytoma. Acta Endocrinol (Copenh) 36:549

13. Peuler JD, Johnson GA (1977) Simultaneous single isotope radioenzymatic assay of plasma norepinephrine, epinephrine and dopamine. Life Sci 21:625

14. Raisanen J, Shapiro B, Glazer GM, Desai S, Sisson JC (1984) Plasma catecholamines in pheochromocytoma : effect of urographic contrast media. AJR 143:43

15. Shapiro B, Sisson JC, Lloyd R, Satterlee W, Beierwaltes WH (1984) Malignant pheochromocytoma: clinical, biochemical and scintigraphic characterization. Clin Endocrinol 20:189

16. Shapiro B, Copp JE, Sisson JC, Eyre PL, Wallis J, Beierwaltes WH (1985) Iodine metaiodobenzylguanidine for the locating of suspected pheochromocytoma: experience in 400 cases. J Nucl Med 26:576

17. Von Euler US, Lishajko F (1959) The estimation of catecholamines in urine. Acta Physiol Scand 45:122 